\title{
The Role of Drama in Task-based Learning: Agency, Identity and Autonomy
}

\section{Lorna Carson}

\begin{abstract}
Drama is a genre which connects the public and private, the rehearsed and the spontaneous, the self and the other. These intriguing relationships may be examined, from an applied linguistic perspective, through the concepts of agency, autonomy and identity. This paper discusses the role of drama in university language learning within a task-based framework, and draws from an example of a collaborative drama task designed for postgraduate students in an English for Academic Purposes programme. It explores how the ideas of agency, autonomy and identity can help conceptualise this type of curricular activity, and presents the design and implementation of a dramatic task, and reviews learner evaluation of the task's perceived impact as an alternative learning approach which lowers affective barriers, the benefits and challenges of a collaborative task, and perceived growth in language proficiency.
\end{abstract}

\section{Introduction}

This paper is based on a plenary address at the "Theatre in University Language Teaching" international seminar, hosted by the Dipartimento di Lingue e Letterature Anglo-Germaniche e Slave at the Università degli Studi di Padova. It discusses the role of drama in university language learning within a task-based framework, and draws from an example of a collaborative drama task designed for postgraduate students in an English for Academic Purposes programme. The first part of my paper explores how the ideas of agency, autonomy and identity can help conceptualise this type of curricular activity, and describes how dramatic tasks can fit into the language classroom. The second part presents the design and implementation of a dramatic task, and reviews learner evaluation of the task's perceived impact as an alternative learning approach which lowers affective barriers, the benefits and challenges of a collaborative task, and perceived growth in language proficiency. ${ }^{1}$

\footnotetext{
${ }^{1}$ I'm grateful to Dr Deirdre Murphy, who gathered the student evaluations discussed below, and to Dr Fiona Dalziel, for her invitation to participate in the international seminar on theatre in university language teaching.
} 


\section{Agency, autonomy and identity}

Drama is a genre which provides regular and intriguing paths connecting the public and private, the rehearsed and the spontaneous, self and the other. The relationships between, on one hand, introspection, subjectivity and the focus on the individual, and, on the other, performance, intersubjectivity and the collective, may perhaps be illuminated by examining the concepts of agency, autonomy and identity as studied in the field of applied linguistics. Various taxonomies place these three terms at different levels within theoretical models, and the three concepts are themselves boundary-crossing notions in the humanities and social sciences - defined and investigated in different ways by philosophers, social psychologists, sociologists, and so on. I briefly describe and define each concept individually (although acknowledging how they interconnect), as a preface to my discussion of how dramatic genres and techniques afford opportunities for enhanced language learning processes and products. In doing so, I follow van Lier's (2010) tripartite delineation of agency, autonomy and identity as essential aspects of the human condition. I will draw on van Lier's explorations of these concepts in more detail below.

\subsection{Agency}

Turning firstly to agency, it may be understood as an individual (or collective) capacity for self-awareness and self-determination: decision-making, ability to enact or resist change, and take responsibility for actions. This anthropological or psychological understanding of agency (rather than grammatical or semiotic, another area of enquiry) forms a body of study within applied linguistics and its preoccupation with the task of how second (and foreign) languages are learned. Van Lier (2010) deftly captures the nature of us-as-agents in a world of other agents by describing how agency refers both to "the ways in which, and the extents to which, a person is compelled to, motivated to, allowed to, and coerced to, act", and equally, "the person deciding to, wanting to, insisting to, agreeing to, and negotiating to, act" (van Lier 2010: $\mathrm{x}$, emphasis in the original). This tension between object and subject echoes Freire's (1996) fundamental assumption that our ultimate human condition is to become a responsible Subject, to act upon and transform the world around us; subjects know and act, whilst objects are only known and acted upon and lack the power to transform and enact. Van Lier (2008) proposes three core features of agency relevant to the study of classroom language learning. The first feature is initiative, or "self-regulation by the learner or group"; the second feature is interdependency - "it mediates and is mediated by the sociocultural context"; the final feature is "an awareness of the responsibility for one's own actions vis-à-vis the environment, including affected others". He uses agency as the umbrella term for these subject-rather-than-object discussions and analysis, but points readers towards another way of approaching the same concepts - this time, under the umbrella term of autonomy. 


\subsection{Autonomy}

The study of autonomy within this paradigm of action and responsibility is best encapsulated by the work of David Little, who stresses, like Freire, the ontological impetus to take control and to do things for ourselves and conceptualises autonomy as a "capacity for detachment, critical reflection, decision-making, and independent action" (Little, 1991: 4). One of the most important contributions of the work of both Little and van Lier in illuminating this very fundamental aspect of the human psyche, the compulsion to act, to take initiative and control, is their articulation of what Conte and Castelfranchi (1995) term bounded autonomy, the relations of dependence that link agents. Van Lier describes (2010: x) the "Janus-faced nature of autonomy", which looks in two directions at the same time, to the personal and to the social, to "myself" and to "the other". Little emphasises that the freedom that learner autonomy implies is always conditional and constrained: "because we are social beings, our independence is always balanced by dependence, our essential condition is therefore one of interdependence" (Little 1991: 5). There may be a certain amount of definitional overlap for some between agency and autonomy. Whilst these terms are closely related, they tend not to be used interchangeably. It can be helpful to understand agency in terms of an individual's actions (determined by self or others), and to recall Little's definition of autonomy as a psychological capacity that is ultimately or successfully expressed in selfdetermined actions. In the related literature on motivation and self-regulation, and the specific role of agency (and how it is delineated from autonomy), I refer readers to Deci and Ryan's theory of motivation, self-determination theory (2002). Within this school of motivational studies, the nuanced interplay between what may be understood as agency and autonomy is illuminated in the two of the essential elements of the theory of self-determination, that (1) humans have inherent tendency toward growth development and integrated functioning, and (2) optimal development and actions are inherent in humans but they don't happen automatically (Deci and Vansteenkiste 2004).

\subsection{Identity}

Studies of human identity (see e.g. Elliott, 2011, for an overview; Kaufman, 2004; Giddens, 1991; Bakhtin, 1981) help articulate how various facets of selfhood contribute towards achieving personal goals, relating to other agents and other agents' goals, and how the tightrope of interdependence is negotiated, successfully or otherwise, in different domains of life including the language classroom. Riley distinguishes between identity in the sense of "personal identity", an enduring sense of the self articulated in and through a repertoire of discursive positions ("social identity"), defining and delimiting the individual and what is common to all individuals. In this conceptualisation, the Self is private and subjective, the source of individual agency, and the Person is public and intersubjective, the site of social identity (Riley 2010: 376-79). Other instances of this type of conceptualisation can be traced to Bakhtin's (1981) 
discussion of identity and the dialogic, how individual identity fluctuates depending on and within contexts, or within sociocultural perspectives on language learning, which engage with how an 'L2 identity' may be constructed and mediated by language and language learners (see, e.g. Kramsch, 2000). Agency, autonomy and identity are powerful, multi-faceted constructs. But, surely the pressing and practical implications of our discussion so far only point us to the perennial obstacles of the formal language classroom? Lack of communication, lack of engagement, lack of participation. Do we have to leave our identities, agency and autonomy at the classroom door, or can learners develop L2 identities, and individual/social agency and autonomy within the language classroom? The next section examines how the use of drama in the language classroom can foster authentic involvement, communication and engagement.

\section{Task-based learning and drama}

Task-based language pedagogy is an increasingly well-explored area in applied linguistics (Legutke and Thomas, 1991; Prabhu, 1991; Willis and Willis, 2007), with some robust attempts to define and delineate the nature, scope and purpose of a task in the language classroom. One of the common denominators that links the many weak and strong definitions of task-based learning (ranging, for instance, from once-off exercises to more structured and extensive activities) is the emphasis on authenticity - that tasks should help learners become language users, in a situationally authentic way, and/or with interactional authenticity (Ellis 2003). Skehan (1998) provides a helpful schema to determine what may be considered a task in the area of formal language learning:

- Does it engage learners' interest?

- Is there a primary focus on meaning?

- Is there an outcome?

- Is success judged in terms of outcome?

- Is completion a priority?

- Is the activity something that occurs in 'real life'?

Using drama in the language classroom (Stern 1980; Healy, 2004; Ryan-Scheutz and Colangelo 2004; Dalziel et al. 2011) seems therefore to be a credible way of fostering both situational and interactional authenticity in language use. The benefits of improvised dramatic activities and rehearsal are particularly relevant to what Dougill (1987: 6-8) refers to as "unpredictability in language use": language is by its very nature unplanned, and every statement is open to any one of a number of responses. Dougill cites the example of a role-play 
in which neither student is aware of the other's role as a means of replicating this situation, where, "[d]rama activities help to bridge the gap between the cosy and controlled world of the classroom and seemingly chaotic composition of language in the world outside". Healy (2004) also touches on the balance between "collaboration and risk-taking". Scripted drama also provides the opportunity to create imagined roles and situations with authentic contexts for meaning-focussed L2 interaction; Maley and Duff (2005: 1) highlight the ability of drama to recreate a communicative event: "[b]y fully contextualising the language, it brings the classroom interaction to life through an intense focus on meaning". With these points in mind, when we apply Skehan's schema (1998) to drama, we can affirm that:

- Drama engages learners' interest, both as participants and as audience members

- There is a primary focus on meaningis a concrete outcome (individually, from short utterances to extended monologues, and from sketches/one act plays through to full productions)

- Assessment is based on the outcome (whether in rehearsal or performance)

- Completion is therefore vital, at least to the extent that utterances are delivered

- It is a real-life activity. Everyone is familiar with drama although they may never have been involved in acting or production.

Having set out a brief rationale for tasks which involve drama in the language classroom, we now turn to a closer examination of their design and organisation.

\section{Design and implementation of dramatic tasks in the language classroom}

The English for Academic Purposes (EAP) programme at Trinity College Dublin has two interconnected strands: intensive pre-sessional modules before the start of the academic year, and weekly in-sessional modules during term-time. Both programmes are offered to students who are not native-speakers of English, and have grown to cater for up to two hundred language learners. The EAP curriculum is delivered through group tasks with spoken and written components, and students are expected to maintain their own individual portfolio of work. The chief aim of the EAP programme is to equip postgraduate students with English language support sufficient for their needs in the academic domain. The proficiency levels required for successful functioning at fourth-level are aligned with the Common European Framework of Reference (CEFR) common proficiency level C1. At C1 level, a non-native speaker of 
English is expected to be able to understand a wide range of demanding, longer texts, and recognize implicit meaning; to express him/herself fluently and spontaneously without too much obvious searching for expressions; to use the English language flexibly and effectively for academic, professional and social purposes; and to produce clear, well-structured, detailed text on complex subjects.

The challenges of such a programme, and the rationale for using drama in the curriculum, is the agreed need (both 'perceived' by teachers and the university, and 'expressed' by students and supervisors) to provide multiple opportunities for different types of output and different types of discourse, given the variety of roles that a postgraduate student necessarily assumes as researcher, student, conference presenter, lab partner, and so on. Students engage with many different interlocutors, for a variety of purposes, and most lack confidence, to give one example, in distinguishing between different types of discourse, and in speaking in public settings.

The curriculum designed for this programme is intended to foster lifelong, autonomous language learning. The task-based learning approach makes use of authentic academic resources to engage learners in real-life academic tasks with both oral and written components, organised in sets of group tasks which provide the curriculum's overall thematic content and structure. Currently four main tasks are used in the EAP programme (one task per week, pre-sessional modules; up to two tasks per term, in-sessional modules):

- Conducting an academic seminar

- Discussing and debating current affairs

- Compiling and publishing publicity brochures

- Producing a short drama to be performed in class.

The drama task outlines the production of a short dramatic sketch to be performed in English at the end of a group of sessions in front of an audience comprising class-members and other classes where possible. Students are asked to write, in groups, either an adaptation of an existing piece of work or to create an original piece for production. Suggestions of genre are provided. Group members must also contribute to a programme/flyer which can function as a location for advertising, biographies, and critical reviews. A task overview and general guidelines are provided for students, and reproduced here:

Overview:

In your group, create a short drama to be performed in class. This can be either an adaptation or original work, e.g. murder mystery, segment of an existing film or novel, modern version of a traditional folk story or fairy tale. Each member of your group should take one or more parts, and also help create a programme/flyer, which may include advertising, biographies and critical reviews. 
Guidelines:

- The drama should take about 15-20 minutes to perform

- The presentation must be interactive: students must interact and communicate with one another during the presentation

- Make sure that each member of your group has an adequate speaking role

- Students must not read from the script during the presentation (you are of course welcome to use prompts/notes). Don't worry if you get stuck and cannot remember what you intended to say: try to improvise, or ask the others in the group to help you out

- At the end of the presentation, the assessors will spend a few minutes asking questions to each member of the group.

The schematic categories provided within the Common European Framework of Reference help specify the activities and competences involved in such tasks, and the types of strategies that learners may deploy, acknowledging the importance of ludic, imaginative, artistic and aesthetic uses of language (Council of Europe 2001: 55), which simultaneously involve productive, receptive, interactive and mediating activities. The task specification provided for students contains the following statement of learning goals, derived from the illustrative scales of the Common European Framework of Reference:

Drama Project C1 proficiency level: learning goals

- In this task you will learn to deliver a short piece of drama in fluent English using stress and intonation to convey finer shades of meaning precisely.

- In selecting your theme and writing your script you will learn to summarise information from different sources in a coherent and succinct manner scanning quickly through texts to locate relevant details.

- As you write your script you will learn to draft well-structured and developed descriptions and imaginative text in a style appropriate to the audience in mind.

This text in the task specification was derived from scaled descriptions of the activities and strategies involved in delivering public announcements (C1/C2 level descriptor), processing text (C2 level descriptor), coherence and cohesion (C2 level descriptor), reading for orientation (B2/C1/C2 level descriptor), and creative writing ( $\mathrm{C} 1$ level descriptor).

Students can be expected to deploy a range of strategies as they plan, execute, evaluate and monitor completion of the steps involved in this task, (ibid: 63), including, for instance:

- Locating and creating resources 
- Considering their audience

- Rehearsing (individually and as a group)

- Adjusting the task to suit individuals/group

- Adjusting the product to suit the audience/time-frame

- Compensating (for lack of time/resources/knowledge)

- Building on previous knowledge

- Piloting their final product

- Self-correcting/improving.

The drama task described here was carried out in a pre-sessional EAP module in 2010, in a class of eleven postgraduate students (eight different nationalities; eight female and three male students, aged 22-50, from a variety of academic disciplines). As for previous group tasks, the drama project was prepared almost entirely in class, in approximately one hour of class time for five days, before the task's performance. Group One performed a parody of the fairy tale of Snow White and the Seven Dwarfs, renamed Snow Ball, Group Two did an abridged version of Jane Austen's Pride and Prejudice.

Over the course of the following four days, the groups prepared and rehearsed the content of their dramas. This involved a variety of sub-tasks:

- Group discussions to determine the topic of the drama, establish the plot outline and allocate characters to each participant;

- For those group members unfamiliar with the chosen story, online research to find the original story;

- Reading extracts from the original novel and watching selected scenes from the film adaptation, to understand the story and to practise pronunciation (Group Two only);

- Script-writing 1: Composing individual scripts (by each group member for his/her own dialogue, or by designated group members);

- Script-writing 2: Combining all individual scripts into a single script (by the whole group or by one designated group member);

- Reading through scripts together to rehearse dialogue, and to check and practise pronunciation;

- Reading through individual script while watching film in order to practise pronunciation (Group Two only); 
- Creating an advertising poster

- Making costumes and props.

After five hours of preparation, the groups performed in front of the class, with costumes, sets and props. After both performances, students reviewed the successes and difficulties of the drama task in a class discussion, and details of their evaluation shared below. In their written evaluation of the drama project, students were encouraged to describe positive and negative aspects of their experience, in the preparation and performance of their task. We focus on three themes that emerged from their evaluations: experiencing an alternative learning approach/lowering affective barriers; benefits and challenges of group work; enhanced language proficiency.

\section{Discussion}

This section discusses student feedback regarding drama as an alternative learning approach, the benefits and challenges of group projects, and the perceived linguistic outcomes of the drama task. Students provided positive feedback about the way the drama project brought them together with other learners, given the isolating nature of postgraduate study in general, and the focus elsewhere in the EAP course on individual work. One student remarked that he had never been involved in any drama before, and thoroughly enjoyed the opportunity to play a character: "When you are ... asked to act someone, to act someone is not you; it's very interesting because ... I didn't do this before." Another student found it enhanced her memory: "I'm more dynamic. I think it stays more in my memory when there is some performing, people actually doing things rather than writing or filling gaps, you know". Performance seemed to lower students' inhibitions in the classroom. One student with previous experience of drama described how in the drama project the students were "learning through emotion... your mind is freer - you are not stressed". She believed that the task of performing the drama project was so absorbing that she forgot about the element of English instruction and focussed only on the performance: "I was thinking [about] the production only....I was unaware we were in an English course".

Krashen's (1981) hypotheses regarding second language acquisition propose that a learner's 'affective filter' is impacted by a number of psychological variables, such as self-esteem and levels of stress and anxiety. Learners who feel stressed and anxious in the classroom are unlikely to take risks or participate in activities. Drama seems to be a powerful way of drawing learners into a task unlike other traditional language learning tasks. From learners' comments above, the balance of rehearsal and performance seems to create a space within which learners can be more fully themselves both as individuals and corporately. We now turn to examine their experiences of group-tasks in more detail.

The drama project provided an opportunity for students to share individual strengths, talents and identities within the context of an English language 
learning project. For instance, students in each group who had a keen interest in art took on responsibility for the production of the poster and costumes. One student mentioned this ability to play to each student's strengths as one of the highlights of group work: "I prefer working in groups. I think you get more when you put people together ... we use what each of us know the best". Another student from Group Two spoke of his enjoyment of the intercultural interaction that went along with group work. He claimed that it gave students the opportunity to share information about their own countries and to learn more about the other students: "The most interesting thing is that people [come] from different backgrounds so ... we talked not only [about] the project, we talked [about] other things, very interesting things."

The two groups did not seem to progress with the same ease through the tasks involved. Group Two showed close collaboration and teamwork at every stage of the project preparation, and the students seemed to be thoroughly enjoying themselves throughout. One of this group's members attributed the positive atmosphere to the example set by a small number of the group: "If there's two or three people very active, the rest ... will follow them." Another student emphasised the importance of a positive group dynamics to the successful outcome of the project, and praised her own group for its camaraderie: "Everyone was really enthusiastic so it was really easy". This contrasted with that of Group One, struggling with the task's preparation. There was initial difficulty in establishing the exact storyline of the performance that persisted throughout the week, with a rather tense start to their performance. Students described a lack of "cooperation" between two group members as the most difficult aspect of executing the project, and how the group dynamic suffered when the same two members failed to follow the decisions that had been made by the group in the previous day's meeting. These group members also stressed that these challenges ultimately proved to be relatively minor, and failed to deter their overall enjoyment of the project. Much of what is described above regarding students' experiences of group work aligns with the 'real-world' reality of collaborative activities: at times frustrating, unfair, with difficulties in assigning roles and activities, but also enjoyable, productive and enabling ("you get more when you put people together ... we use what each of us know the best").

Understanding the constructs of agency, autonomy and identity here can provide an insight into what goes on within the catch-all label of 'group-work': Group Two suffers for instance when two individuals work at cross purposes. There remains much to learn about the nature of the group dynamic, particularly the concept of 'bounded autonomy' (Conte and Castelfranchi, 1995) in the language classroom, and the use of drama seems to mirror the complexities of real-life and our essential interdependency (Little, 1991), learners as agents in a world of other agents (van Lier, 2010). In the next section, we examine the third theme that emerged from students' in-class and written evaluations of the drama task.

In their spoken and written evaluations, students were asked to describe 
the aspect of their English language learning that they felt had benefited most from participation in the drama task. Their responses covered a wide range of language skills, including perceived improvements in the areas of speaking (confidence), listening, reading, vocabulary range and control, confidence/automaticity of language use and phonological control. Reading and vocabulary related to reading the original story and working together as a group to produce the play's script from this source document. In this section on perceived impact on language learning outcomes, we concentrate on two specific areas of improvement mentioned by students: confidence/automaticity of language use and phonological control.

One student described how her confidence in her ability to speak English in front of others had grown substantially since taking part in the drama project: "For me it's really good because when you pretend to be someone else it's easier to talk in front of people". Another student highlighted the role of drama in helping the learner to improvise: "I really think it [drama] improves your speaking qualities in front of a public ... [The aspect of my English that most improved was] the retrieving of information when you have to improvise or to change something." A member of Group One attributed her improved pronunciation during the performance to a lowered 'affective filter', "When your mind is busy thinking [about] the performance, you don't think too much 'My pronunciation's very bad!' You are more - spontaneous I suppose ... I'm not aware". A member of Group Two described how the pressure of performing in front of an audience helped her focus on accuracy: "When I'm speaking the dialogues I know that somebody will watch me, therefore [I try to be] more precise than before!"

Students' perceptions of enhanced language learning outcomes are vital, especially when these may be accompanied by a misconception of the purposes of a language programme (where students, on arrival, may expect a grammarfocussed course, or a conversation class, for example). These types of perceived enhanced outcomes of course could be investigated in a more systematic way, and matched, for example, with the traditional assessed outcomes of a course. Nevertheless, the drama task engendered positive perceptions of enhanced learning in students, and the development of L2 identities as spontaneous language users, comfortable with their growing social identity as an L2 English speaker.

\section{Conclusion}

The evaluative feedback received from university language learners involved in the drama task indicates how a real-life communicative framework can be constructed within the walls of a classroom. Within such a framework, we see that authentic or 'real-life' (simultaneously enabling, frustrating, uncomfortable, productive) communication takes place. Of course, it helps that learners are keen to use the target language for their own academic and personal goals, and that the target language is the lingua franca of the 
classroom. Nevertheless, it can be argued that there is something very special about the nature of drama which allows students to engage powerfully with each other, to draw on their own personal stories, and to generate both 'off-line' and 'on-line' communication. It is in the very interaction, the to and fro, between the rehearsed and performed, the private and the public, the exploratory and then planned, that learners grow in awareness both of the language learning process, and of the nature of their language learning products or utterances. In this task-based framework, learners plan, prepare and cooperate in unpredictable communicative situations and with challenges of the group dynamic, yet with the support of scripted communication and in the perspective of a final performance. One key question we are currently addressing in this programme is how students' own backgrounds, cultural sensibilities and learning preferences have an impact on their level of involvement and satisfaction with group learning, drama and task completion. An empirical investigation of collaboration learning is underway, examining the student experience of task-based learning from a longitudinal perspective.

The interaction described above by students, which echoes my earlier conceptualisations of agency, identity and autonomy, is a powerful indicator of where learners are stretched and pulled, and where they push and grow. This recalls van Lier's (2010) distinction between ways in which learners are "compelled to, allowed to act", versus "how learners decide to, want to, agree to, and negotiate to, act". Learners become co-agents, visibly interdependent both in the dramatic process and product. This creates a vital living bridge between the individual and the social. This bridge (which can be understood as real-life or authentic communication) is mostly artificial in a language classroom context: accepted by all to be a necessary ill, and lessened somewhat by the group's decision to pretend to engage in the 'social' and to present an acceptable 'individual' face for the sake of the classroom dynamic; authentic interaction only takes place outside the classroom door and after class, rarely in the target language.

This present paper has presented a conceptualisation of task-based learning that is located within a discussion of agency, autonomy and identity. It has argued that the use of drama in such a framework fulfils the schema for an authentic task, apt to meet the learning needs of language students, and to foster progress in second and foreign language learning. Drama tasks such as those outlined here allow for communication between "personal identity" and "social identity" (Riley 2010). Until learners act as themselves in the language they are learning, and learn to express their personal identity, they remain artificially trapped in social representation and unable to express individual needs and wants; in the words of Giddens (1991: 70), "What to do? How to act? Who to be?" 


\section{Bibliography}

Bakhtin, Mikhail; Holquist, Michael; Emerson, Caryl (1981): The Dialogic Imagination. Austin, TX: University of Texas Press

Borge, Sheree (2007): The Use of Drama Activities in Teaching German in a Third-level Classroom. In: Scenario, I/1, 1-27

Conte, Rosario; Castelfranchi, Cristiano (1995): Cognitive and Social Action. London: UCL Press

Dalziel, Fiona; Santucci, Anna; Spedo, Giampaolo (2011): Rewriting the 'Duchess of Malfi': Adapting Webster's Tragedy for an ESL Drama Production. In: Scenario, V/1, 5-20

Deci, Edward; Ryan, Richard (2002): Handbook of Self-Determination Research. Rochester, (NY): University of Rochester Press

Deci, Edward; Vansteenkiste, Maarten (2004): Self-Determination Theory and Basic Need Satisfaction: Understanding Human Development in Positive Psychology. In: Ricerche di Psichologia, 27, 17-34

Dougill, John (1987): Drama Activities for Language Learning. London: Macmillan

Elliott, Anthony (2011): Routledge Handbook of Identity Studies. London: Routledge

Ellis, Rod (2003): Task-Based Language Learning and Teaching. Oxford: Oxford University Press

Freire, Paolo (1996): Pedagogy of the Oppressed. London: Penguin

Giddens, Anthony (1991): Modernity and Self-Identity: Self and Society in the Late Modern Age. Cambridge: Polity Press

Healy, Celine (2004): Drama in Education for Language Learning. In: Humanising Language Teaching 6/3. Retrieved from http://www.hltmag.co.uk/sept04/mart7.htm (last accessed 12/04/2012).

Kaufman, Jean-Christophe (2004): L'Invention de Soi: Une Théorie de l'Identité. Paris: Armand Colin

Kramsch, Claire (2000): Social Discursive Constructions of Self in L2 learning. In: Lantolf, James (2000, ed.): Sociocultural Theory and Second Language Learning. New York: Oxford University Press

Krashen, Stephen (1981): Principles and Practice in Second Language Acquisition. London: Prentice-Hall International

Legutke, Michael; Thomas, Howard (1991): Process and Experience in the Language Classroom. London: Longman

Little, David (1991): Learner Autonomy 1: Definitions, Issues, Problems. Dublin: Authentik

Maley, Alan; Duff, Alan (2005): Drama Techniques in Language Learning: A Resource Book of Communication Activities for Language Teachers. Cambridge: Cambridge University Press 
O'Rourke, Breffni; Carson, Lorna (eds.) (2010): Language Learner Autonomy: Policy, Curriculum, Classroom. Oxford: Peter Lang

Prabhu, N.S. (1991): Second Language Pedagogy. Oxford: Oxford University Press

Riley, Philip (2010): Reflections on Identity, Modernity and the European Language Portfolio. In: O’Rourke, Breffni; Carson, Lorna (eds.) (2010), Language Learner Autonomy: Policy, Curriculum, Classroom. Oxford: Peter Lang

Ryan-Scheutz, Colleen; Marini-Maio, Nicoletta (2004): Dramatic Interactions: Teaching Languages, Literatures, and Cultures through Theater, Theoretical Approaches and Classroom Practices. Newcastle: Cambridge Scholars

Skehan, Peter (1998): A Cognitive Approach to Language Learning. Oxford: Oxford University Press

Stern, Susan (1980): Drama in Second Language Learning from a Psycholinguistic Perspective. In: Language Learning 30/1, 77-100

van Lier, Leo (2008): Agency in the Classroom. In: Lantolf, James; Poehner, M. (eds.): Sociocultural Theory and the Teaching of Second Languages. London: Equinox

van Lier, Leo (2010): Agency, Self and Identity in Language Learning. In: O'Rourke, Breffni; Carson, Lorna (eds.) (2010), Language Learner Autonomy: Policy, Curriculum, Classroom. Oxford: Peter Lang

Willis, Dave; Willis, Jane (2007): Doing Task-Based Teaching. Oxford: Oxford University Press 